\title{
Cisplatin decreases cyclin D2 expression via upregulating miR-93 to inhibit lung adenocarcinoma cell growth
}

\author{
NING XIE ${ }^{*}$, YUAN-RONG LIU ${ }^{2 *}$, YAN-MEI LI ${ }^{1}$, YA-NAN YANG ${ }^{2}$, LI PAN $^{2}$, \\ YU-BO WEI ${ }^{2}$, PING-YU WANG ${ }^{2}$, YOU-JIE $\mathrm{LI}^{2}$ and SHU-YANG XIE ${ }^{2}$ \\ ${ }^{1}$ Department of Chest Surgery, Yantaishan Hospital, Yantai, Shandong 264000; \\ ${ }^{2}$ Department of Biochemistry and Molecular Biology, Key Laboratory of Tumor Molecular Biology in Binzhou \\ Medical University, Binzhou Medical University, Yantai, Shandong 264003, P.R. China
}

Received February 3, 2019; Accepted July 11, 2019

DOI: $10.3892 / \mathrm{mmr} .2019 .10566$

\begin{abstract}
MicroRNAs (miRNAs/miRs) serve important roles in the chemotherapeutic effect of anticancer drugs. To investigate the roles of miRNAs in cisplatin-induced suppression of lung adenocarcinoma cell proliferation, A549 cells were treated with different concentrations of cisplatin. An MTT assay demonstrated that cisplatin inhibited A549 cell proliferation in a dose-dependent manner. Cisplatin induced cell apoptosis and inhibited cell migration by increasing the levels of miR-93, miR-26a and miR-26b. Furthermore, as an upstream factor, miR-93 was proposed to regulate cyclin D2 expression in miR-93-transfected A549 cells. Cisplatin also induced $\mathrm{Bcl}-2$-associated $\mathrm{X}$ protein expression, and decreased that of Bcl-2 and c-Myc in lung adenocarcinoma cells. In vivo analysis further supported that cisplatin inhibited lung adenocarcinoma cell growth by regulating cyclin D2 and miR-93 expression. In conclusion, our findings demonstrated that cisplatin could effectively inhibit lung adenocarcinoma cell proliferation by decreasing cyclin D2 expression via miR-93.
\end{abstract}

\section{Introduction}

Lung cancer is one of the most common types of cancer and has the highest mortality rates worldwide (1). Non-small cell lung cancer (NSCLC) accounts for $>80 \%$ of cancer-associated mortalities (2). With the development of scientific technology, notable progress has been achieved in the early diagnosis and treatment of various tumor types. A tumor can be completely

Correspondence to: Professor Shu-Yang Xie, Department of Biochemistry and Molecular Biology, Key Laboratory of Tumor Molecular Biology in Binzhou Medical University, Binzhou Medical University, 346 GuanHai Road Yantai, Shandong 264003, P.R. China E-mail: shuyangxie@aliyun.com

*Contributed equally

Key words: microRNA, cisplatin, cyclin D2, cell proliferation, lung cancer removed in the early stage of disease, although it may recur in half of the patients who undergo the process (1). According to statistics, the majority of patients with lung cancer are diagnosed in the advanced stages, at which the prognosis is very poor and the 5-year survival rate is $<16 \%$ (3). Platinum-based chemotherapy is the primary treatment modality for NSCLC. However, adverse treatment outcomes, including drug resistance, may result in failure of chemotherapy (4).

MicroRNAs (miRNAs/miRs) are single-stranded non-coding RNAs of 20-22 nucleotides, which participate in gene expression and are involved in regulating post-transcriptional expression (5). miRNAs influence the proliferation, differentiation and apoptosis of cancer cells (5). It has been reported that miRNAs participate in tumor formation, which provides opportunities for the optimization of cancer treatment (6). miRNAs function as tumor promotors or inhibitors; thus, they serve critical roles in tumor occurrence and development, which is important not only in the diagnosis and prediction of prognosis, but also in developing novel therapeutic strategies for tumor treatment $(7,8)$. The expression of miR-21 in plasma and tissue samples from patients with NSCLC could be used to predict the survival index and chemotherapy effect of platinum-based drugs (9).

miRNAs have also reported to be relevant to the potential toxicity mechanism (10) and the antitumor activity of drugs in several tumor types, including breast cancer (6), lung, colorectal (11) and esophageal cancer (12). Blower et al (13) identified that overexpression of miR-7i, miR-16 and miR-21 miRNA improved the chemotherapeutic effect of an anticancer drug in NSCLC cell lines. miR-539 could increase the chemosensitivity of NSCLC cells to cisplatin by directly targeting double cortin like kinase 1 (DCLK1) (14). Zhang et al (15) reported that by regulating glutathione $\mathrm{S}$-transferase pi gene expression, miR-513a-3p could increase the sensitivity of a lung adenocarcinoma cell line to cisplatin. These studies indicate that miRNAs serve important roles in the anticancer activity of cisplatin.

Although it is understood that miRNAs serve important roles in the chemotherapeutic effect of anticancer drugs, the roles of miRNAs in cisplatin-induced suppression of lung cancer proliferation require further investigation. Therefore, the present study aimed to investigate the effects of cisplatin on the expression of miRNAs and the proliferation of lung cancer cells. 


\section{Materials and methods}

Chemicals and supplements. The following drugs and reagents were used in the present study: Fetal calf serum (Hyclone; GE Healthcare), trypsin (Sigma-Aldrich; Merck KGaA), RPMI-1640 culture medium (Sigma-Aldrich; Merck KGaA), DMSO (Sigma-Aldrich; Merck KGaA), 3-(4,5-dimethylthiazol-2-yl)-2,5-diphenyltetrazolium bromide (MTT; Sigma-Aldrich; Merck KGaA), penicillin/streptomycin (100 x; Gibco; Thermo Fisher Scientific, Inc.), cisplatin (Qilu Pharmaceutical Co., Ltd.), SYBR Green PCR master mix quantification PCR kit (Qiagen, Inc.), $5 \mathrm{X}$ poly A buffer, $\mathrm{MgCl}_{2}$, and dATP (Promega Corporation), dNTP mixture and RNase inhibitor (Takara Bio, Inc.).

Cell lines and cell culture. To investigate the roles of cisplatin in the proliferation of lung cancer cells, the A549 cells were used in this study, which is a lung cancer cell line and provided by the Institute of Shanghai Cell Biology $(16,17)$. All cells were cultured in RPMI-1640 medium supplemented with $10 \%$ fetal bovine serum, $100 \mathrm{IU} / \mathrm{ml}$ penicillin, and $100 \mu \mathrm{g} / \mathrm{ml}$ streptomycin sulfates at $37^{\circ} \mathrm{C}$ with $5 \% \mathrm{CO}_{2}$. Cells $\left(1 \times 10^{4}\right)$ seeded in the 96-well flat bottom microtiter plates were respectively treated with $0,3,6$ and $9 \mu \mathrm{g} / \mathrm{ml}$ of cisplatin for $24-72 \mathrm{~h}$ at $37^{\circ} \mathrm{C}$ as our previous report (17). Then the cells were observed under a microscope (with magnification $100 \mathrm{x}, \mathrm{BX} 43$, Olympus, Inc., Japan) at $48 \mathrm{~h}$ after treatment.

MTT assay. Cell proliferation assays were performed using a modified colorimetric MTT assay, according to the manufacturer's protocols. All procedures were repeated a minimum of three times, as described in our previous studies $(18,19)$. Absorbance was measured at $570 \mathrm{~nm}$ using an ELISA reader (Multiskan FC; Thermo Fisher Scientific, Inc).

Cell apoptosis assay. Apoptosis was measured using BD FACSDiva Software on a flow cytometer (BD FACSCantoTM ${ }^{\mathrm{II}}$, BD Bioscience) after $48 \mathrm{~h}$ of incubation with $0,3,6$ or $9 \mu \mathrm{g} / \mathrm{ml}$ cisplatin. Briefly, cells $\left(1 \times 10^{5} /\right.$ well of a 12 -well flat-bottom microtiter plate) were stained with Annexin V-FITC/PI (Nanjing KeyGen Biotech. Co. Ltd.), according to the manufacturer's protocols.

Cell migration assay. To monitor cell migration, cells $\left(1 \times 10^{4}\right.$ cells/well) were seeded onto the top chamber of a CIM plate (xCELLigence). The cells were incubated at room temperature for $30 \mathrm{~min}$, and CIM plates were placed on an RTCA station (xCELLigence System; Roche, Diagnostics $\mathrm{GmbH}$ ). Real-time monitoring of cell migration was conducted for $24 \mathrm{~h}$ by detecting the changes of electrical impedance at the electrode/cell interface.

Reverse transcription-quantitative PCR (RT-qPCR). A549 cells and tumor xenografts were harvested at $48 \mathrm{~h}$ following cisplatin treatment. miRNAs was isolated from the cells using mirVana $^{\mathrm{TM}}$ miRNA kit (Ambion; Thermo Fisher Scientific, Inc.) and ploy (A) was added using poly (A) polymerase (2 $\mathrm{U} / \mu \mathrm{l}$; Ambion; Thermo Fisher Scientific, Inc.). cDNA was synthesized by incubating the reaction at $37^{\circ} \mathrm{C}$ for $1 \mathrm{~h}$ with a specific primer (5'-AACATGTACAGTCCATGGATGd(T)30N(A,G,C or T)-3'). qPCR was performed to detect miRNA levels using TB Green ${ }^{\circledR}$ Premix Ex Taq ${ }^{\mathrm{TM}}$ kit (RR420A, Takara Bio Company), as described previously (18) on a StepOnePlusTM Real-Time PCR Systems (Version 2.3, life technologies). The following thermocycling conditions were used: $95^{\circ} \mathrm{C}$ for $5 \mathrm{~min}$ followed by 40 cycles of $95^{\circ} \mathrm{C}$ for $30 \mathrm{sec}, 60^{\circ} \mathrm{C}$ for $20 \mathrm{sec}$ and $72^{\circ} \mathrm{C}$ for $20 \mathrm{sec}$. The following forward primer sequences were used: miR-93, 5'-CAAAGTGCTGTTCGT GCAGGTA-3'; miR-26a, 5'-CAAGTAATCCAGGATAGG C-3'; miR-26b, 5'-CAAGTAATCCAGGATAGGT-3'; miR-29a, 5'-GCACCATCTGAAATCGGTTA-3'; miR-29c, 5'-GCACCA TTTGAAATCGGTTA-3'; and miR-125b, 5'-TCCCTGAGA CCCTAACTTGTG-3'. The reverse primer used to amplify these miRNAs was: 5'-AACATGTACAGTCCATGGATAG-3'. Human 5S rRNA was used as the control with the following primer sequences: Forward 5'-GCCATACCACCCTGA ACG-3', and reverse 5'-AACATGTACAGTCCATGGATG-3'. The data was calculated using the $2^{-\Delta \Delta C q}$ method (20). All assays were performed in three triplicates.

miRNA mimics and transfection. The human miR-93 duplex mimic (miR-93; 5'-caaagugcuguucgugcagguag-3') and control oligos (Mock; 5'-ccuacgccaccaauuucgu-3') were obtained from Shanghai GenePharma Co., Ltd. Lung cancer cells $\left(2 \times 10^{5}\right)$ were transfected with $1.5 \mu \mathrm{g}$ miRNA using $2.5 \mu 1$ Lipofectamine ${ }^{\circledR} 2000$ (Invitrogen; Thermo Fisher Scientific, Inc.), according to the manufacturer's protocols. miRNAs and total protein were extracted from cells $48 \mathrm{~h}$ after transfection.

miRNA target genes. TargetScanHuman Release 7.2 (http://www.targetscan.org/vert_72/) was used to predict the biological targets of miRNAs. The target genes and their miRNA binding sites were predicted using this online tool.

Western blotting. The cells were lysed with radioimmunoprecipitation assay buffer (Beyotime Institute of Biotechnology) at $4^{\circ} \mathrm{C}$ on ice for $30 \mathrm{~min}$. After centrifugation in $13,400 \mathrm{x}$ g for $5 \mathrm{~min}$ at $4^{\circ} \mathrm{C}, 30 \mu \mathrm{g}$ of protein was separated by $10 \%$ SDS-PAGE and transferred onto a nitrocellulose membrane. The blots were incubated with rabbit anti-human cyclin D2 (1:400; cat. no. 10934-1; Proteintech Group, Inc.)/Bcl-2-associated X protein (Bax; 1:400; cat. no. BS2583; Bioworld Technology, Inc.)/Bcl-2 (1:400; cat. no. 12789-1; Proteintech Group, Inc.)/c-Myc (1:400; cat. no. BS2462; Bioworld Technology, Inc.)//-actin (1:400; cat. no. BS-0061R; Beijing Biosynthesis Biotechnology Co., Ltd.) antibodies at $4^{\circ} \mathrm{C}$ overnight. Membranes were washed with TBS and Tween-20 (TBST) three times. HRP-labeled goat anti-rabbit $\operatorname{IgG}(1: 6,000$; cat. no. BS13278; Bioworld Technology, Inc.) was then added for $1 \mathrm{~h}$ at room temperature. Finally, signals were captured using enhanced chemiluminescence (Wuhan Boster Biological Technology, Ltd.) after three washes with 1X TBST. The assays were performed in triplicate. Densitometry was performed using a Gel Image System 4.2 (Tanon Science \& Technology Co., Ltd.).

In vivo study. In total, 6 four-week old male athymic BALB/c mice $(15 \mathrm{~g})$ were purchased from Beijing HFK Bioscence Co., Ltd. The mice were kept at $22 \pm 2^{\circ} \mathrm{C}$ with a humidity of $50 \pm 5 \%$ 
A

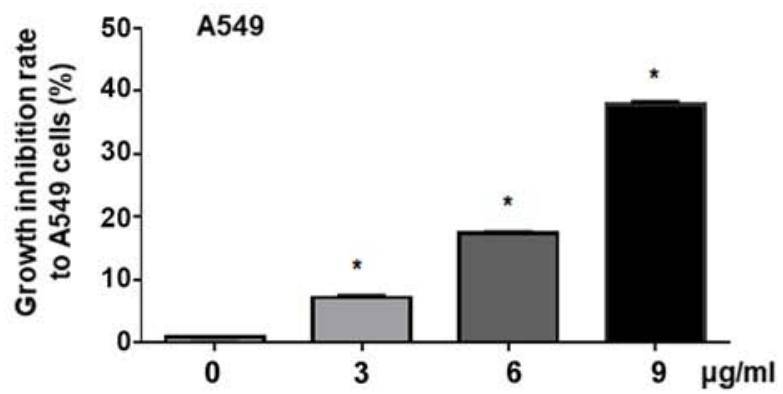

B

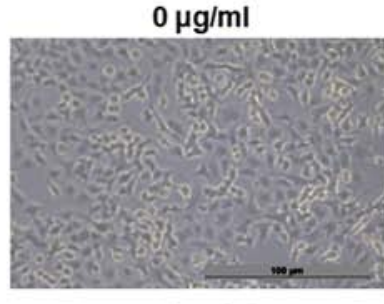

$6 \mu \mathrm{g} / \mathrm{ml}$

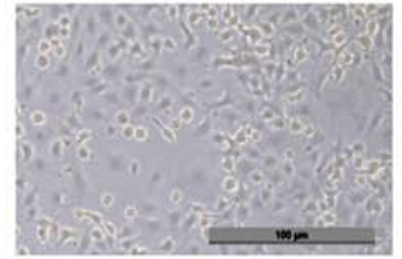

$3 \mu \mathrm{g} / \mathrm{ml}$

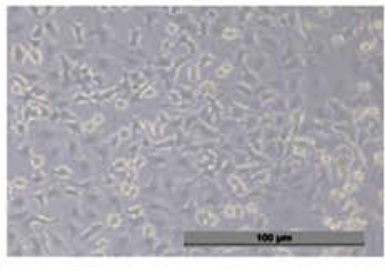

$9 \mu \mathrm{g} / \mathrm{ml}$

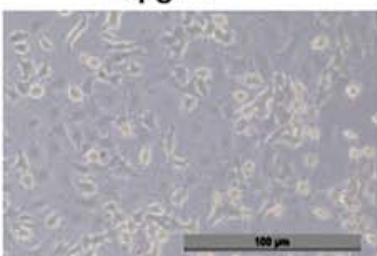

Figure 1. Effects of cisplatin on the growth of lung adenocarcinoma cells. (A) Growth inhibition rate. Cisplatin significantly inhibited A549 cell proliferation in a dose-dependent manner. ${ }^{*} \mathrm{P}<0.05$ vs. $0 \mu \mathrm{g} / \mathrm{ml}$. (B) Morphological changes of A549 cells. Fewer living cells were identified in the cisplatin-treated lung adenocarcinoma cultures compared with the untreated control. Scale bar, $100 \mu \mathrm{m}$.

in $20 \times 40 \times 60 \mathrm{~cm}$ cages, with a $12 \mathrm{~h}$ light/dark cycle and were fed with a standard diet and water. Each mouse was subcutaneously injected with an A549 cell suspensions $\left(5 \times 10^{6}\right.$ cells in $0.1 \mathrm{ml}$ of PBS) into the armpit area. The experimental group $(\mathrm{n}=3)$ was treated with cisplatin $(3 \mathrm{mg} / \mathrm{kg})$ by intraperitoneal injection, while the control group $(n=3)$ was treated with an equal volume of saline. All mice were sacrificed after 4 weeks and tumors were collected. All animal experiments were approved by the Ethics Committee of Animal Experiments of Binzhou Medical University.

Statistical analysis. SPSS 22.0 software (IBM Corp.) was used to analyze the data. Experiments were performed in triplicate and the data are presented as the mean \pm SD. The comparison between two groups was analyzed using an unpaired two-sided Student's t-test. The comparisons among three or more groups were analyzed by One-way ANOVA. If the results had statistical significance, the comparison between two groups was performed using Bonferonni's tests. $\mathrm{P}<0.05$ was considered to indicate a statistically significant difference.

\section{Results}

Cisplatin suppresses the proliferation of lung adenocarcinoma cells. In our previous study, it was identified that cisplatin could inhibit A549 cell proliferation by upregulating the expression of MutS homolog 2 through miR-21 (17). To further investigate the mechanism of cisplatin-induced suppression of lung adenocarcinoma cell growth, the present study treated A549 cells with different concentrations of cisplatin. MTT analysis results demonstrated that cisplatin significantly inhibited the proliferation of A549 cells in a dose-dependent manner compared with the control $(0,3,6$ and $9 \mu \mathrm{g} / \mathrm{ml}$, Fig. 1A). Morphological analysis revealed that the treatment with cisplatin $(3,6$ and $9 \mu \mathrm{g} / \mathrm{ml})$ for $24 \mathrm{~h}$ suppressed A549 cell viability, compared with the untreated control cells $(0 \mu \mathrm{g} / \mathrm{ml}$, Fig. 1B). This indicated that cisplatin could effectively suppress lung adenocarcinoma cell proliferation in a dose-dependent manner.
Cisplatin induces apoptosis and inhibits the migration of A549 cells. Next, the current study detected the roles of cisplatin in regulating the apoptosis and migration of lung adenocarcinoma cells. The results demonstrated that the percentage of apoptotic cells in 3, 6 and $9 \mu \mathrm{g} / \mathrm{ml}$ cisplatin-treated cultures was $14.4,23$ and $28.7 \%$, respectively, higher than the $8.6 \%$ determined in the control treatment. The percentage of apoptotic cells was elevated in cisplatin-treated A549 cells in a dose-dependent manner, particularly in the $9 \mu \mathrm{g} / \mathrm{ml}$ cisplatin-treated cells (Fig. 2A). The migration of A549 cells was analyzed using a RTCA station, which demonstrated that treatment with 6 and $9 \mu \mathrm{g} / \mathrm{ml}$ cisplatin treatment significantly suppressed A549 cell migration (Fig. 2B and C).

miR-93 is upregulated in cisplatin-treated A549 cells. Previous studies have reported that miRNAs exhibit important roles in the regulation of chemotherapy drugs and molecule-targeted drugs $(6,9-12,14,15)$. miR-93, miR-26a, miR-26b, miR-29a, miR-29c and miR-125 have been reported to exert important roles in cancers (21-24). To further investigate the roles of these miRNAs in cisplatin-induced inhibition of lung cancer cell proliferation, RT-qPCR was used to detect changes in the expression of six miRNAs, including miR-93, miR-26a, miR-26b, miR-29a, miR-29c and miR-125b, in cisplatin-treated A549 cells. The results demonstrated that the levels of miR-29c were significantly increased following treatment with $9 \mu \mathrm{g} / \mathrm{ml}$ cisplatin; compared with the control, significant increases in the expression of miR-26b were detected in response to 3 and $6 \mu \mathrm{g} / \mathrm{ml}$ cisplatin, while $3 \mu \mathrm{g} / \mathrm{ml}$ cisplatin significantly induced miR-29a expression. Of note, treatment with all concentrations resulted in the significant upregulation of miR-93 and miR-26a compared with the control (Fig. 3).

miR-93 regulates the expression of cyclin $D 2$. miR-93 has been reported to promote the apoptosis and increase the percentage of human umbilical vein endothelial cells in G1 phase by targeting angiopoietin 2 (25). The present study further revealed that that cyclin D2 is a novel target gene of miR-93 using TargetScanHuman 7.2 software online 

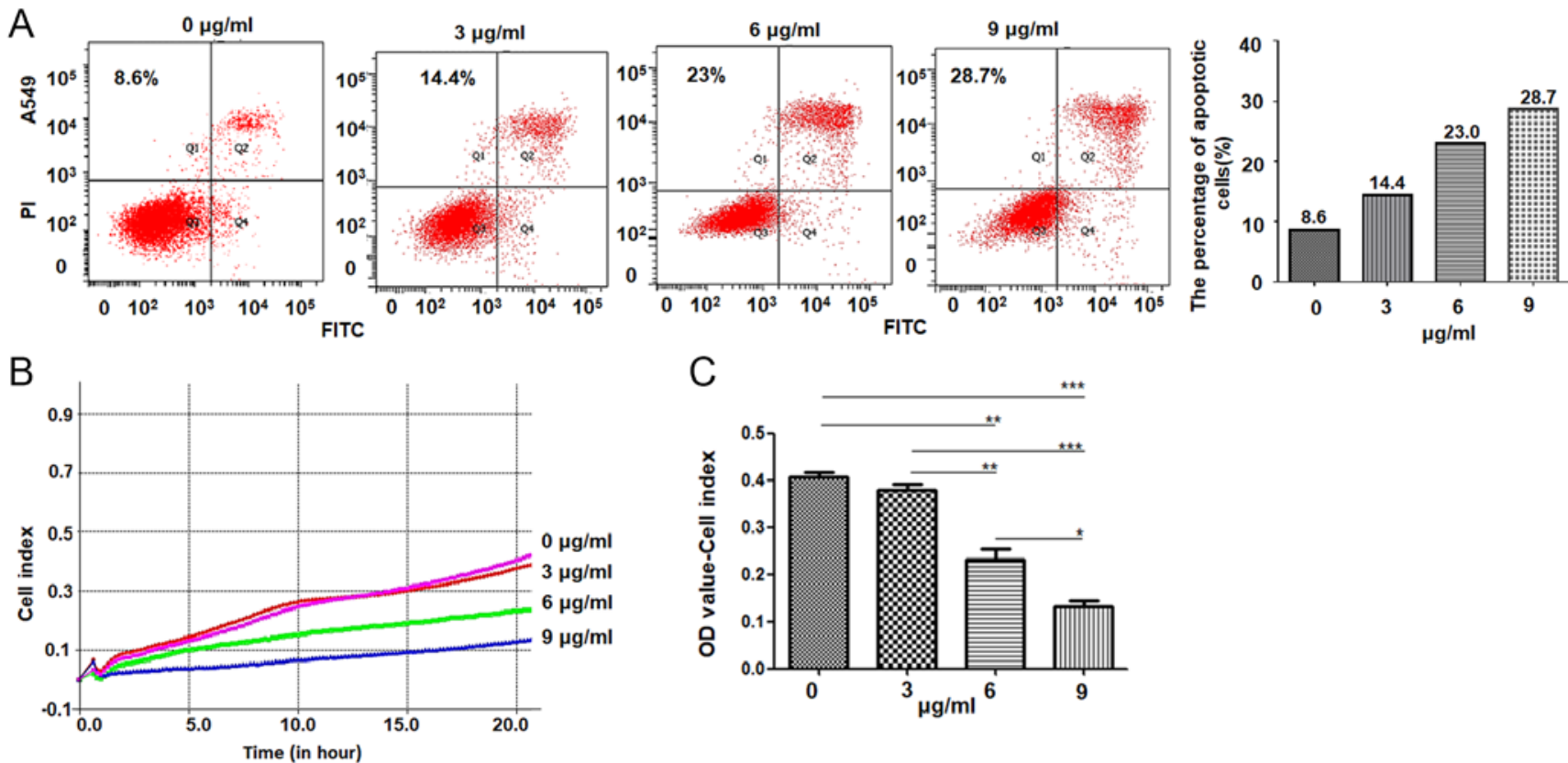

Figure 2. Cisplatin induces apoptosis and suppresses cell migration. (A) Apoptosis of A549 cells. More apoptotic cells were detected in the cisplatin-treated groups compared with the control. * $\mathrm{P}<0.05$ vs. $0 \mu \mathrm{g} / \mathrm{ml}$. (B) Real-time monitoring of cell migration using a CIM plate. (C) Quantification of the number of migrated cells. Treatment with 6 and $9 \mu \mathrm{g} / \mathrm{ml}$ cisplatin treatment effectively inhibited lung cancer cell migration. ${ }^{*} \mathrm{P}<0.05,{ }^{* *} \mathrm{P}<0.01,{ }^{* * *} \mathrm{P}<0.001$. FITC, fluorescein isothiocyanate; OD, optical density; PI, propidium iodide.
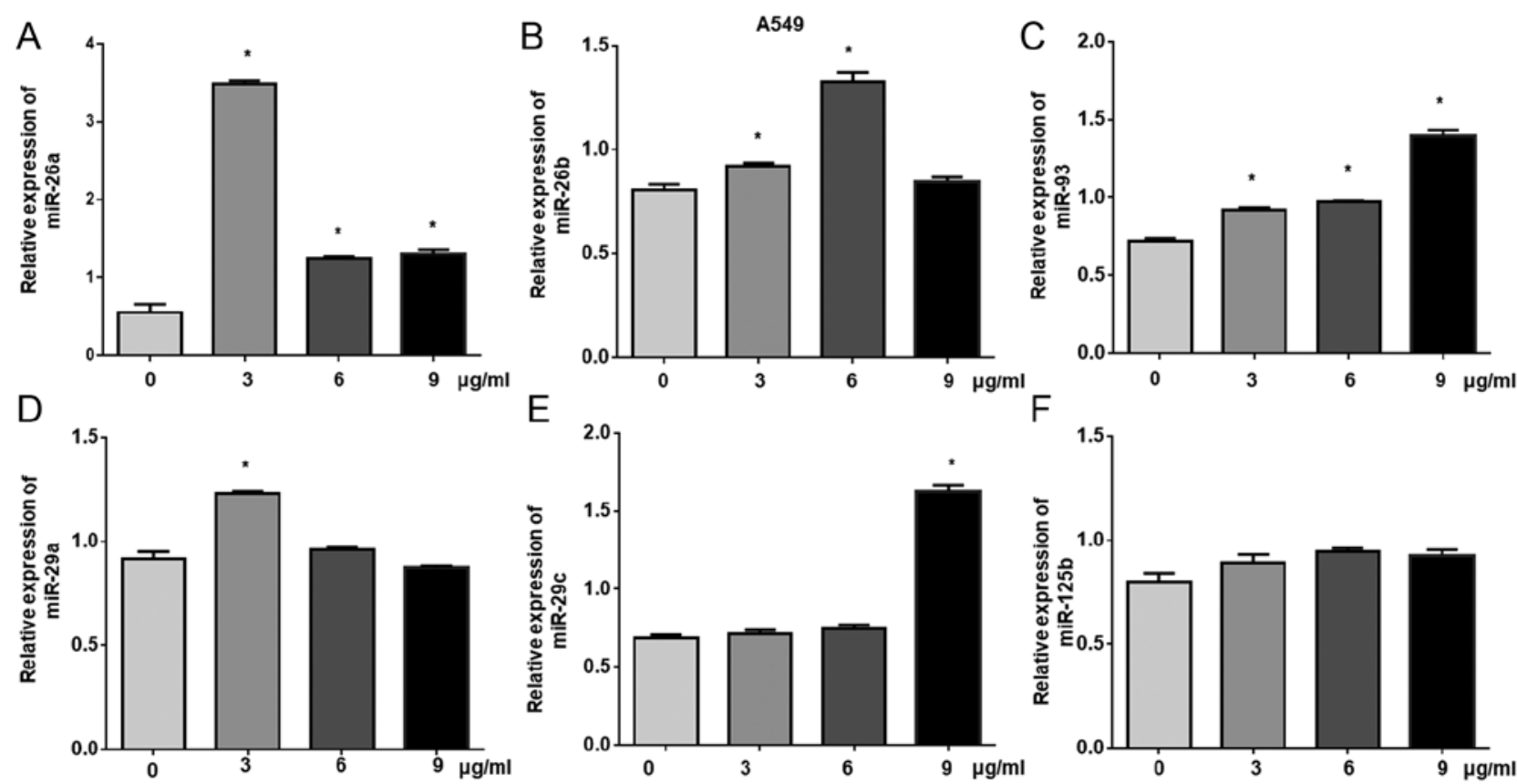

Figure 3. Cisplatin affects the expression of miRs in A549 cells. (A-F). The expression levels of miR-26a, miR-26b, miR-93, miR-29a, miR-29c and miR-125b in cisplatin-treated A549 cells were detected by reverse transcription-quantitative polymerase chain reaction. The levels of miR-93, miR-26a, miR-26b, miR-29a and miR-29c revealed significant increases in expression in response to certain concentrations of cisplatin. "P<0.05 vs. $0 \mu \mathrm{g} / \mathrm{ml}$. miR, microRNA.

(Fig. 4A). Subsequently, A549 cells were transfected with miR-93 to investigate whether miR-93 could regulate cyclin D2 expression as an upstream factor (Fig. 4B). Western blot analysis showed that overexpression of miR-93 significantly reduced the expression of cyclin D2 in miR-93-transfected A549 cells compared with control cells (Fig. 4C and D), which indicated that miR-93 decreased the expression of cyclin D2 as an upstream factor.
Cisplatin suppresses cell growth by decreasing cyclin D2 expression via miR-93. The aforementioned results indicated that cisplatin suppresses lung cancer cell growth by upregulating miR-93 expression, which negatively regulates cyclin D2 expression. To further investigate whether cisplatin suppresses cell growth by decreasing cyclin D2 expression via miR-93, cyclin D2 levels were detected by western blotting following cisplatin treatment. Our results revealed that 
A

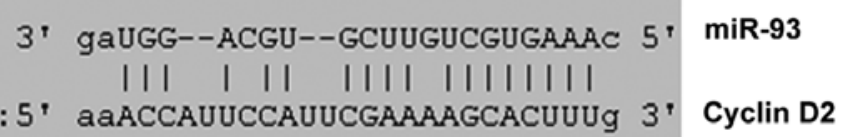

\section{C $\quad \mathbf{A 5 4 9}$}

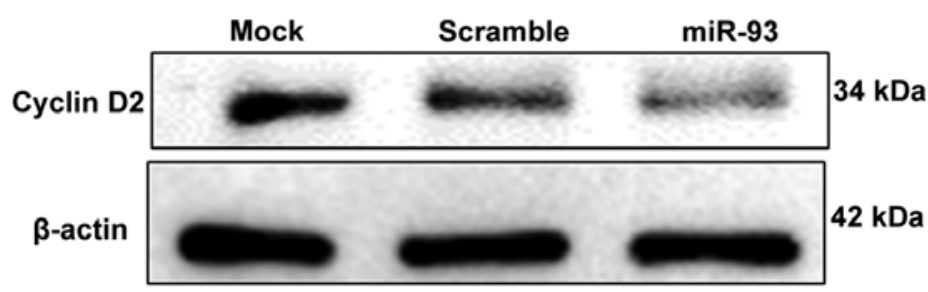

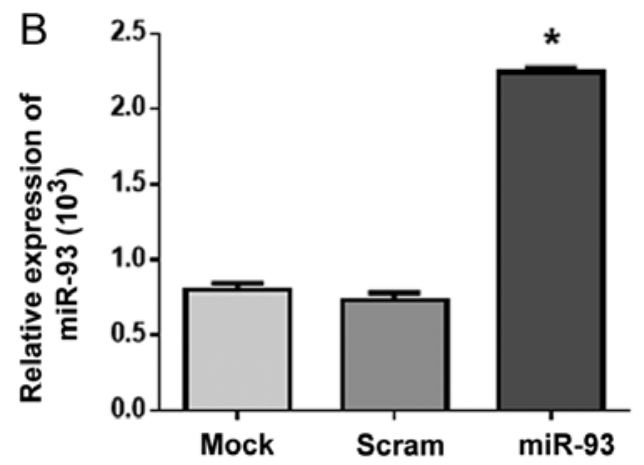

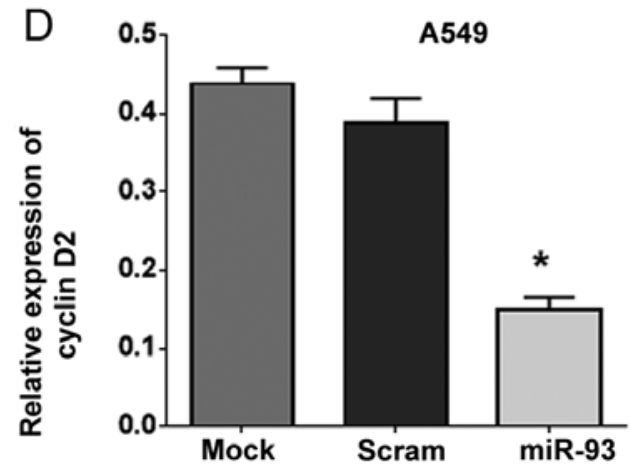

Figure 4. Cyclin D2 is regulated by miR-93. (A) The 3'untranslated region of cyclin D2 mRNA contains a binding site for miR-93. (B) Reverse transcription-quantitative polymerase chain reaction analysis. The levels of miR-93 were increased following transfection with miR-93. * $<<0.05$ vs. mock and scram. (C) Western blot analysis. miR-93 suppressed cyclin D2 expression in A549 cells. (D) Densitometry analysis of the relative expression levels of cyclin $\mathrm{D} 2 / \beta$-actin in A549 cells. ${ }^{*} \mathrm{P}<0.05$ vs. mock and scram. miR, microRNA.

A

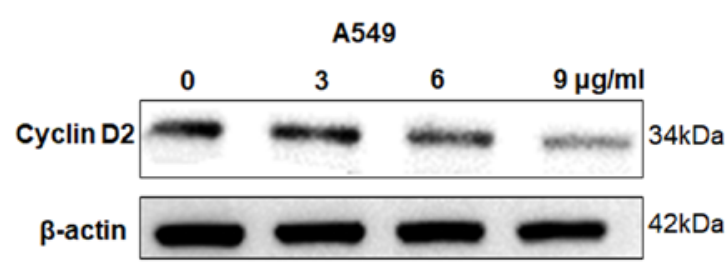

B

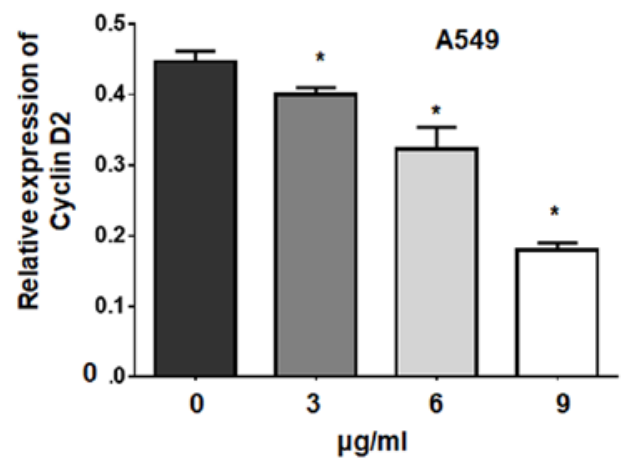

Figure 5. Cisplatin suppresses cyclin D2 expression via miR-93. (A) Western blot analysis. Cisplatin suppressed cyclin D2 expression in A549 cells. (B) Densitometry analysis of the relative expression level of cyclin D2/ $\beta$-actin in cisplatin-treated A549 cells. * P<0.05 vs. $0 \mu \mathrm{g} / \mathrm{ml}$.

cisplatin significantly downregulated cyclin D2 expression in A549 cells in a dose-dependent manner compared with the control (Fig. 5). These results suggest that cisplatin suppresses cell growth by decreasing cyclin D2 expression via miR-93.

Cisplatin affects the expression of apoptosis-associated proteins. Additionally, the expression levels of apoptosis-associated proteins, including Bcl-2, Bax and c-Myc, were detected by western blot analysis. The results demonstrated that cisplatin significantly reduced the expression of c-Myc and Bcl-2, but increased Bax levels in a dose-dependent manner compared with the control (Fig. 6). This indicated that cisplatin-induced cell apoptosis is associated with the regulation of c-Myc, Bcl-2 and Bax expression.
Cisplatin suppresses A549 cell growth in vivo. To evaluate the roles of cisplatin and miR-93 in regulating cell proliferation in vivo, A549 lung cancer xenografts were established in BALB/c nude mice. The results demonstrated that tumor volumes and weights were markedly decreased in cisplatin-treated xenografts compared with controls (Fig. 7A-C). RT-qPCR revealed that miR-93 expression was significantly increased in cisplatin-treated xenografts compared with the control treatment (Fig. 7D). Cyclin D2, the predicted target of miR-93, was notably downregulated in tumors treated with cisplatin compared with in control tumors (Fig. 7E), which supports the hypothesis that cisplatin suppresses A549 cell growth in vivo via miR-93 and cyclin D2. 

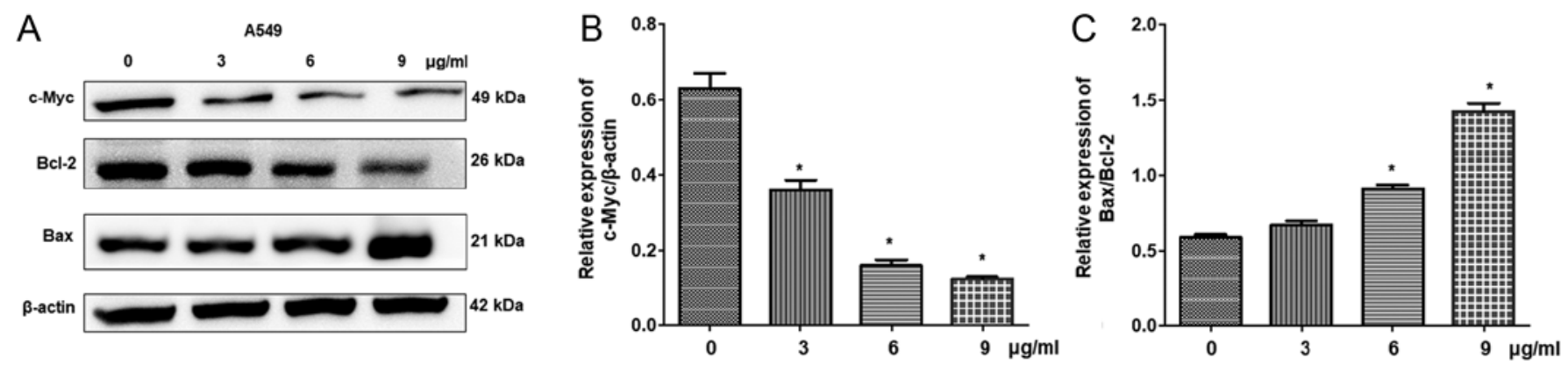

Figure 6. Cisplatin regulates the expression of apoptosis-associated genes. (A) Western blot analysis. (B) Densitometry analysis of the relative expression level of c-Myc/ $\beta$-actin. (C) Densitometry analysis of the relative expression level of Bax/Bcl-2. Cisplatin decreased c-Myc and Bcl-2, and increased Bax levels in A549 cells. ${ }^{*} \mathrm{P}<0.05$ vs. $0 \mu \mathrm{g} / \mathrm{ml}$. Bax, Bcl-2-associated X protein.
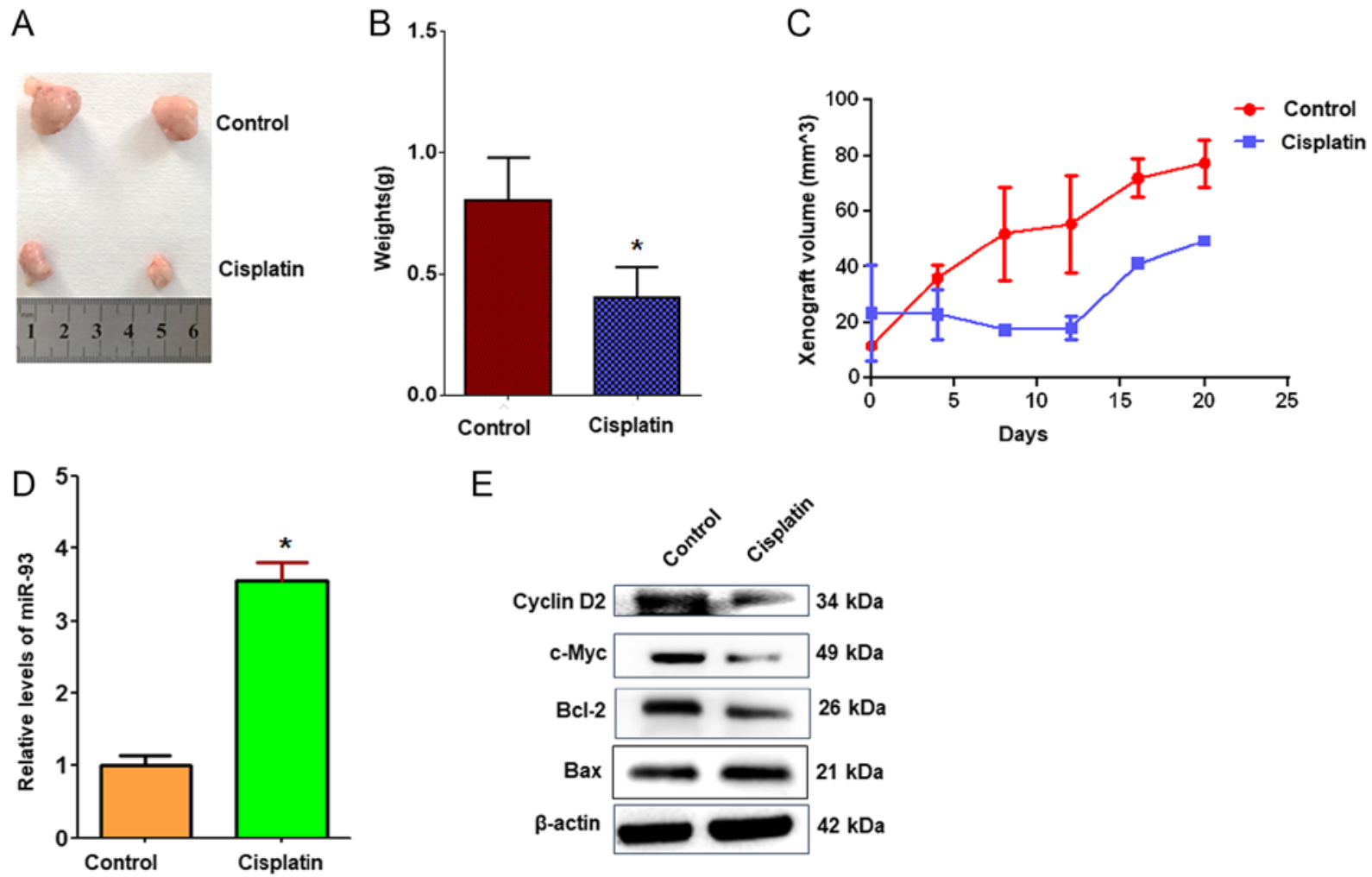

Figure 7. Cisplatin suppresses the growth of lung cancer cell xenografts in vivo. (A) Lung cancer xenografts. Cisplatin suppressed the growth of A549 lung cancer xenografts in BALB/C-nude mice. (B) Tumor weight. Tumor weight was significantly reduced in cisplatin-treated xenografts compared with the controls ( $(\mathrm{P}<0.05$ vs. control, $\mathrm{n}=3$ ). (C) Alterations in tumor volume. The volume of A549 lung cancer xenografts were reduced in BALB/C nude mice following cisplatin treatment. (D) Reverse transcription-quantitative polymerase chain reaction analysis. The levels of miR-93 increased in cisplatin-treated cell xenografts ( $\mathrm{P}<0.05$ vs. control, $\mathrm{n}=3$ ). (E) Western blot analysis. The levels of cyclin $\mathrm{D} 2$, c-Myc and Bcl-2 decreased, while Bax increased, in cisplatin-treated cell xenografts. Bax, Bcl-2-associated X protein.

\section{Discussion}

Noncoding RNAs, including miRNAs, are involved in a number of pathological conditions of cancer (26). miRNAs are responsible for the development of resistance to anticancer drugs as they affect drug resistance-associated genes, and induce alternative signaling pathways and the DNA damage response (26). miR-205 can significantly induce apoptosis and enhance chemotherapeutic effects in prostate cancer cells (27). Furthermore, ethanol extract of Antrodia cinnamomea can inhibit the growth of breast cancer cells by increasing the expression levels of miR-21-5p, miR-26-5p and miR-30-5p (28). The interaction of phosphoinositide 3-kinase with seven in absentia homolog 2 is regulated by the miRNA-30-5p family and is considered as a potential treatment target in NSCLC (29). The aforementioned miRNAs serve important roles in enhancing tumor sensitivity toward targeted therapies. The present study selected miR-93, which was significantly increased in lung adenocarcinoma cells after cisplatin treatment. Additionally, it was demonstrated that cyclin D2 is a direct target of miR-93, and miR-93 and cyclin D2 were reported to serve important roles in cisplatin-induced lung adenocarcinoma cell apoptosis.

Platinum-based drugs, particularly cisplatin, are first-line chemotherapy drugs (30). miRNAs are involved into the 
mechanism of cisplatin for the treatment of cancer $(14,31,32)$. The epigenetic regulation of insulin like growth factor 1 receptor via miR-1294 is important for cisplatin resistance in ovarian cancer (32). miR-539 can increase the chemosensitivity of lung cancer cells to cisplatin treatment by directly targeting DCLK1 (14). miR-363 may be a biomarker for predicting responsiveness to cisplatin-based chemotherapy by snail-induced epithelial-mesenchymal transition in epithelial ovarian cancer cells (31). Although these studies support that miRNAs participate in the anticancer roles of cisplatin for the treatment of cancer, the effects of cisplatin on the proliferation of lung cancer cells require further investigation. Previous studies found that miR-93, miR-26a, miR-26b, miR-29a, miR-29c and miR-125 play important roles in cancer (22-24). The present study investigated the roles of these miRNAs in the cisplatin-induced suppression of lung cancer and demonstrated that cisplatin could effectively inhibit lung adenocarcinoma cell proliferation in a dose-dependent manner. The mechanism by which cisplatin inhibits lung adenocarcinoma cell proliferation is proposed to be associated with the expression of miR-93 and miR-26a.

miRNAs are involved in numerous biological processes associated with cancer, including carcinogenesis, cell proliferation, invasion and migration, which serve crucial roles in the regulation of tumor development and progression $(33,34)$. Through binding with the 3'-untranlasted region of target mRNAs, miRNAs inhibit targeted gene expression to a certain degree (33). miR-9600, a novel molecule, has been identified to impair its target expression, which inhibits the growth of lung cancer cells (35). miR-93 has been reported to promote the apoptosis and the percentage of cells in the G1 peak of human umbilical vein endothelial cells by regulating its target gene, angiopoietin 2 (25). As miR-93 levels were significantly increased in cisplatin-treated A549 cells, the present study further investigated the targeted gene of this miRNA to evaluate the mechanism of cisplatin-induced lung cancer cell apoptosis. It was proposed that cyclin D2 is a novel target of miR-93, which serves important roles in cisplatin-induced apoptosis and migration.

D-type cyclins, including D1, D2 and D3, serve important roles in the G1 to S phase transition (36). Cyclin D2 acts as a proto-oncogene in several types of cancer (37). Cyclin D2 cytoplasmic localization may reflect an important physiological role in tumor progression (38). Cyclin D2 is overexpressed in $53 \%$ of colon tumors, and correlates to the high metastatic degree of tumors (39). Overexpression of cyclin D2 also correlates with progression and poor prognosis in gastric cancer (38). Aberrant cyclin D2 expression has been demonstrated in human ovarian granulosa cell tumors and testicular germ cell tumor cell lines (40). As a cell cycle regulator, cyclin D2 is regulated by let-7 in lung cancer (41). Similarly, the present study demonstrated that cisplatin inhibited lung cancer cell proliferation by decreasing cyclin D2 levels.

In summary, the current study further investigated the mechanism of cisplatin in the inhibition of lung cancer cell proliferation, which demonstrated that cisplatin could inhibit lung adenocarcinoma cell proliferation and migration in a dose-dependent manner. Furthermore, cisplatin was proposed to effectively inhibit lung adenocarcinoma cell growth by downregulating cyclin D2 via miR-93.

\section{Acknowledgements}

The authors would like to thank Dr Lixia Zhang (Experimental Central Lab of Binzhou Medical University) for help with the analysis of the flow cytometry data.

\section{Funding}

The present study was supported by the National Natural Science Foundation of China (grant nos. 81772281 and 31371321), the Shandong Science and Technology Committee (grant nos. ZR2019MH022, 2017GSF221011 and 2018GSF118056), the Yantai Science and Technology Committee (grant nos. 2016ws044 and 2018XSCC051), Health and Family Planning Commission of Shandong (grant no. 2015WS0499), and the Shandong Province Taishan Scholar Project (grant no. ts201712067).

\section{Availability of data and materials}

The datasets used during the present study are available from the corresponding author upon reasonable request.

\section{Authors' contributions}

SYX conceived and designed the study. NX, YRL, YML, YNY, LP, YBW, PYW, and YJL performed the experiments. NX, YRL and SYX wrote the paper. PYW and SYX reviewed and edited the manuscript.

\section{Ethics approval and consent to participate}

All animal experiments were approved by the Committee on the Ethics of Animal Experiments of Binzhou Medical University.

\section{Patient consent for publication}

Not applicable.

\section{Competing interests}

The authors declare that they have no competing interests.

\section{References}

1. Jemal A, Bray F, Center MM, Ferlay J, Ward E and Forman D: Global cancer statistics. CA Cancer J Clin 61: 69-90, 2011.

2. Smith W and Khuri FR: The care of the lung cancer patient in the 21st century: A new age. Semin Oncol 31 (2 Suppl 4): S11-S15, 2004.

3. Testa U, Castelli G and Pelosi E: Lung cancers: Molecular characterization, clonal heterogeneity and evolution, and cancer stem cells. Cancers (Basel) 10: E248, 2018.

4. Rizvi NA, Hellmann MD, Brahmer JR, Juergens RA, Borghaei H, Gettinger S, Chow LQ, Gerber DE, Laurie SA, Goldman JW, et al: Nivolumab in combination with platinum-based doublet chemotherapy for first-line treatment of advanced non-small-cell lung cancer. J Clin Oncol 34: 2969-2979, 2016.

5. Mens MMJ and Ghanbari M: Cell cycle regulation of stem cells by MicroRNAs. Stem Cell Rev 14: 309-322, 2018.

6. Lou W, Liu J, Gao Y, Zhong G, Ding B, Xu L and Fan W: MicroRNA regulation of liver cancer stem cells. Am J Cancer Res 8: 1126-1141, 2018. 
7. Qadir MI and Faheem A: miRNA: A diagnostic and therapeutic tool for pancreatic cancer. Crit Rev Eukaryot Gene Expr 27: 197-204, 2017.

8. Shomali N, Mansoori B, Mohammadi A, Shirafkan N, Ghasabi M and Baradaran B: MiR-146a functions as a small silent player in gastric cancer. Biomed Pharmacother 96: 238-245, 2017.

9. Gao W, Lu X, Liu L, Xu J, Feng D and Shu Y: MiRNA-21: A biomarker predictive for platinum-based adjuvant chemotherapy response in patients with non-small cell lung cancer. Cancer Biol Ther 13: 330-340, 2012.

10. Ma JG and Li XY: MicroRNAs are involved in the toxicity of microcystins. Toxin Rev 36: 165-175, 2017.

11. Wu QB, Sheng X, Zhang N, Yang MW and Wang F: Role of microRNAs in the resistance of colorectal cancer to chemoradiotherapy. Mol Clin Oncol 8: 528-532, 2018.

12. Hong L, Yang Z, Ma J and Fan D: Function of miRNA in controlling drug resistance of human cancers. Curr Drug Targets 14: 1118-1127, 2013.

13. Blower PE, Chung JH, Verducci JS, Lin S, Park JK, Dai Z, Liu CG, Schmittgen TD, Reinhold WC, Croce CM, et al: MicroRNAs modulate the chemosensitivity of tumor cells. Mol Cancer Ther 7: 1-9, 2008

14. Deng H, Qianqian G, Ting J and Aimin Y: miR-539 enhances chemosensitivity to cisplatin in non-small cell lung cancer by targeting DCLK1. Biomed Pharmacother 106: 1072-1081, 2018.

15. Zhang X,Zhu J,Xing R, Tie Y,Fu H,Zheng X and Yu B: miR-513a-3p sensitizes human lung adenocarcinoma cells to chemotherapy by targeting GSTP1. Lung Cancer 77: 488-494, 2012.

16. Ju J, Chen A, Deng Y, Liu M, Wang Y, Wang Y, Nie M, Wang C, Ding $\mathrm{H}$, Yao B, et al: NatD promotes lung cancer progression by preventing histone $\mathrm{H} 4$ serine phosphorylation to activate slug expression. Nat Commun 8: 928, 2017.

17. Zhang YX, Yue Z, Wang PY, Li YJ, Xin JX, Pang M, Zheng QY and Xie SY: Cisplatin upregulates MSH2 expression by reducing miR-21 to inhibit A549 cell growth. Biomed Pharmacother 67: 97-102, 2013

18. Wang PY, Sun YX, Zhang S, Pang M,Zhang HH, Gao SY, Zhang C Lv CJ and Xie SY: Let-7c inhibits A549 cell proliferation through oncogenic TRIB2 related factors. FEBS Lett 587: 2675-2681, 2013.

19. Zhang YX, Yan YF, Liu YM, Li YJ, Zhang HH, Pang M, Hu JX, Zhao W, Xie N, Zhou L, et al: Smad3-related miRNAs regulated oncogenic TRIB2 promoter activity to effectively suppress lung adenocarcinoma growth. Cell Death Dis 7: e2528, 2016.

20. Livak KJ and Schmittgen TD: Analysis of relative gene expression data using real-time quantitative PCR and the 2(-Delta Delta C(T)) method. Methods 25: 402-408, 2001.

21. Gao Y, Deng K, Liu X, Dai M, Chen X, Chen J, Chen J, Huang Y, Dai S and Chen J: Molecular mechanism and role of microRNA-93 in human cancers: A study based on bioinformatics analysis, meta-analysis, and quantitative polymerase chain reaction validation. J Cell Biochem 120: 6370-6383, 2019.

22. Kwon Y, Kim Y, Eom S, Kim M, Park D, Kim H, Noh K, Lee H, Lee YS, Choe J, et al: MicroRNA-26a/-26b-COX-2-MIP-2 loop regulates allergic inflammation and allergic inflammation-promoted enhanced tumorigenic and metastatic potential of cancer cells. J Biol Chem 290: 14245-14266, 2015.

23. Tan M, Wu J and Cai Y: Suppression of Wnt signaling by the miR-29 family is mediated by demethylation of WIF-1 in non-small-cell lung cancer. Biochem Biophys Res Commun 438: 673-679, 2013.

24. Wang PY, Li YJ, Zhang S, Li ZL, Yue Z, Xie N and Xie SY: Regulating A549 cells growth by ASO inhibiting miRNA expression. Mol Cell Biochem 339: 163-171, 2010.

25. Qian Q, Sun W, Zhu W, Liu Y, Ge A, Ma Y, Zhang Y, Zeng X and Huang $M$ : The role of microRNA-93 regulating angiopoietin2 in the formation of malignant pleural effusion. Cancer Med 6 : 1036-1048, 2017
26. Hahne JC and Valeri N: Non-Coding RNAs and resistance to anticancer drugs in gastrointestinal tumors. Front Oncol 8: 226 , 2018.

27. Nagesh PKB, Chowdhury P, Hatami E, Boya VKN, Kashyap VK, Khan S, Hafeez BB, Chauhan SC, Jaggi M and Yallapu MM: miRNA-205 nanoformulation sensitizes prostate cancer cells to chemotherapy. Cancers (Basel) 10: E289, 2018

28. Lin YS, Lin YY, Yang YH, Lin CL, Kuan FC, Lu CN, Chang GH, Tsai MS, Hsu CM, Yeh RA, et al: Antrodia cinnamomea extract inhibits the proliferation of tamoxifen-resistant breast cancer cells through apoptosis and skp $2 /$ microRNAs pathway. BMC Complement Altern Med 18: 152, 2018.

29. Chan LW, Wang F, Meng F, Wang L, Wong SC, Au JS, Yang S and Cho WC: MiR-30 family potentially targeting PI3K-SIAH2 predicted interaction network represents a novel putative theranostic panel in non-small cell lung cancer. Front Genet 8: 8 , 2017.

30. Zhao L, Li R, and Gan YH: Knockdown of Yin Yang 1 enhances anticancer effects of cisplatin through protein phosphatase 2A-mediated T308 dephosphorylation of AKT. Cell Death Dis 9: 747, 2018.

31. Cao L, Wan Q, Li F and Tang CE: MiR-363 inhibits cisplatin chemoresistance of epithelial ovarian cancer by regulating snail-induced epithelial-mesenchymal transition. BMB Rep 51: 456-461, 2018.

32. Zhang Y, Huang S, Guo Y and Li L: MiR-1294 confers cisplatin resistance in ovarian Cancer cells by targeting IGF1R. Biomed Pharmacother 106: 1357-1363, 2018.

33. Markou A, Sourvinou I, Vorkas PA, Yousef GM and Lianidou E: Clinical evaluation of microRNA expression profiling in non small cell lung cancer. Lung Cancer 81: 388-396, 2013.

34. Price $C$ and Chen J: MicroRNAs in cancer biology and therapy: Current status and perspectives. Genes Dis 1: 53-63, 2014.

35. Sun CC, Li SJ, Zhang F, Zhang YD, Zuo ZY, Xi YY, Wang L and Li DJ: The novel miR-9600 suppresses tumor progression and promotes paclitaxel sensitivity in non-small-cell lung cancer through altering STAT3 expression. Mol Ther Nucleic Acids 5: e387, 2016.

36. Zhang P: The cell cycle and development: Redundant roles of cell cycle regulators. Curr Opin Cell Biol 11: 655-662, 1999.

37. Blanco L and Tirado CA: Testicular germ cell tumors: A cytogenomic update. J Assoc Genet Technol 44: 128-133, 2018.

38. Takano Y, Kato Y, van Diest PJ, Masuda M, Mitomi H and Okayasu I: Cyclin D2 overexpression and lack of p27 correlate positively and cyclin E inversely with a poor prognosis in gastric cancer cases. Am J Pathol 156: 585-594, 2000.

39. Mermelshtein A, Gerson A, Walfisch S, Delgado B Shechter-Maor G, Delgado J, Fich A and Gheber L: Expression of D-type cyclins in colon cancer and in cell lines from colon carcinomas. Br J Cancer 93: 338-345, 2005.

40. Sicinski P, Donaher JL, Geng Y, Parker SB, Gardner H, Park MY, Robker RL, Richards JS, McGinnis LK, Biggers JD, et al: Cyclin D2 is an FSH-responsive gene involved in gonadal cell proliferation and oncogenesis. Nature 384: 470-474, 1996.

41. Johnson CD, Esquela-Kerscher A, Stefani G, Byrom M, Kelnar K Ovcharenko D, Wilson M, Wang X, Shelton J, Shingara J, et al: The let-7 microRNA represses cell proliferation pathways in human cells. Cancer Res 67: 7713-7722, 2007.

(i) $($ ) This work is licensed under a Creative Commons Attribution-NonCommercial-NoDerivatives 4.0 International (CC BY-NC-ND 4.0) License. 